This item was submitted to Loughborough's Research Repository by the author.

Items in Figshare are protected by copyright, with all rights reserved, unless otherwise indicated.

\title{
Lower extremity preventive measures for slips: joint moments and myoelectric analysis
}

PLEASE CITE THE PUBLISHED VERSION

http://dx.doi.org/10.1080/00140130701733301

\section{PUBLISHER}

(C) Taylor \& Francis

\section{VERSION}

AM (Accepted Manuscript)

\section{PUBLISHER STATEMENT}

This work is made available according to the conditions of the Creative Commons Attribution-NonCommercialNoDerivatives 4.0 International (CC BY-NC-ND 4.0) licence. Full details of this licence are available at: https://creativecommons.org/licenses/by-nc-nd/4.0/

\section{LICENCE}

CC BY-NC-ND 4.0

\section{REPOSITORY RECORD}

Fong, Daniel Tik-Pui, Youlian Hong, and Jing-Xian Li. 2019. "Lower Extremity Preventive Measures for Slips: Joint Moments and Myoelectric Analysis". figshare. https://hdl.handle.net/2134/21171. 


\begin{tabular}{|c|c|}
\hline Title & $\begin{array}{l}\text { Lower extremity preventive measures for slips - joint moments and } \\
\text { myoelectric analysis }\end{array}$ \\
\hline Authors & 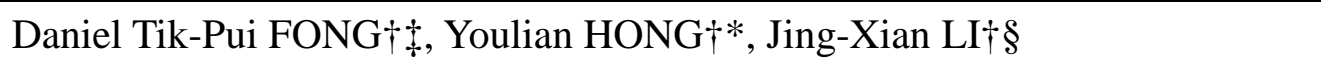 \\
\hline $\begin{array}{l}\text { Affiliations and } \\
\text { postal addresses }\end{array}$ & $\begin{array}{l}\text { †Department of Sports Science and Physical Education, Faculty of Education, } \\
\text { The Chinese University of Hong Kong, Hong Kong, China } \\
\ddagger \text { Department of Orthopaedics and Traumatology, Prince of Wales Hospital, } \\
\text { Faculty of Medicine, The Chinese University of Hong Kong, Hong Kong, } \\
\text { China } \\
\S S c h o o l \text { of Human Kinetics, Faculty of Health Science, University of Ottawa, } \\
\text { Ottawa, Ontario, Canada }\end{array}$ \\
\hline Running head & Lower extremity preventive measures for slips \\
\hline Keywords & $\begin{array}{l}\text { Electromyography; kinetics; biomechanics; slips and falls; fall prevention; } \\
\text { joint torque }\end{array}$ \\
\hline Telephone & $\begin{array}{l}\text { Daniel Tik-Pui Fong (852) } 96020151 \\
\text { Youlian Hong (852) } 26096082 \\
\text { Jing-Xian Li (1-613) } 5625800 \text { ext } 2457\end{array}$ \\
\hline Facsimile & $\begin{array}{l}\text { Daniel Tik-Pui Fong (852) } 26463020 \\
\text { Youlian Hong (852) } 26035781 \\
\text { Jing-Xian Li (1-216) } 5625149\end{array}$ \\
\hline Email & $\begin{array}{l}\text { Daniel Tik-Pui Fong dfong@ort.cuhk.edu.hk / dfong@alumni.cuhk.edu.hk } \\
\text { Youlian Hong youlianhong@cuhk.edu.hk } \\
\text { Jing-Xian Li jli@uottawa.ca }\end{array}$ \\
\hline $\begin{array}{l}\text { Corresponding } \\
\text { author }\end{array}$ & $\begin{array}{l}\text { Youlian Hong, youlianhong@cuhk.edu.hk, } \\
\text { Department of Sports Science and Physical Education, Faculty of Education, } \\
\text { The Chinese University of Hong Kong, Hong Kong, China }\end{array}$ \\
\hline
\end{tabular}




\title{
Lower extremity preventive measures for slips - joint moments and myoelectric analysis
}

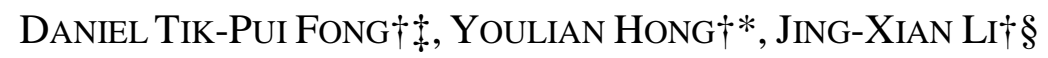

†Department of Sports Science and Physical Education, Faculty of Education, The

Chinese University of Hong Kong, Hong Kong, China

$\ddagger$ Department of Orthopaedics and Traumatology, Prince of Wales Hospital, Faculty of

Medicine, The Chinese University of Hong Kong, Hong Kong, China

$\S S c h o o l$ of Human Kinetics, Faculty of Health Science, University of Ottawa, Ottawa, Ontario, Canada

Keywords: Electromyography; kinetics; biomechanics; slips and falls; fall prevention; joint torque.

*Author for correspondence: Prof Youlian Hong, Human Movement Laboratory, Department of Sports Science and Physical Education, Faculty of Education, The Chinese University of Hong Kong, Hong Kong, China. E-mail: youlianhong@cuhk.edu.hk

This study investigated the lower extremity preventive measures for slips on simulated slippery surfaces in construction worksites. Fifteen harnessed Chinese males walked without slips on a five-metre walkways in sixteen simulated conditions ten times at their natural cadence. Joint moments were calculated from kinetics, kinematics and anthropometric data recorded from a force plate, a Novel Pedar system and a motion analysis system. Data were evaluated from footstrike to mid-stance at $10 \%$-stance intervals. Electromyography signals from tibialis anterior, gastrocnemius, rectus femoris and biceps femoris in one stride were evaluated in four phases including early/late stance and swing. Results showed that lower extremity preventive measures for slips included prolonged ankle plantarflexion moments from $25 \%$ to $92 \%$ stance, increased ankle plantarflexion moments from 30\% stance to mid-stance, and diminished knee extension moments from $10 \%$ to $30 \%$ stance. Higher activity of rectus femoris and gastrocnemius were found in the late stance and the swing phase respectively. 


\section{Introduction}

Slips and falls are the most common causes of occupational accidents worldwide, including the US (United States Department of Labor 1996), the UK (Manning et al. 1988), Finland (Gronqvist and Roine 1993), and Hong Kong (Hong Kong Occupational Safety and Health Council 2003). Numerous biomechanics studies on slips and falls mechanisms have been conducted in order to identify the hazards to pedestrians in different settings, including in the load carrying situation (Bentley and Haslam 1998, Myung and Smith 1997), in elderly participants (Lockhart et al. 2003), on inclined walkways (Leroux et al. 2002, Redfern and DiPasquale 1997), and on slippery level walking surfaces (Cham and Redfern 2001, Cham and Redfern 2002, Marigold et al. 2003, Marigold and Patla 2002, Myung and Smith 1997). The findings of these previous studies have been mainly on friction measurement on different surfaces (Hanson et al. 1999) and the gait kinematics changes during human recovery action (Cham and Redfern 2001, Marigold et al. 2003). These findings have provided good knowledge about human adaptation to slips. Most of the studies measured the kinematics and kinetics of the adaptation outcome, and only a few measured the mechanism or neuromuscular control of such adaptation.

Biomechanics studies of neuromuscular aspects can help in the understanding of 
the mechanism of musculoskeletal adaptation leading to safe gait. These studies include internal joint forces and moments studies (Cham and Redfern 2001), as well as electromyographic studies (Kadaba et al. 1985). The neuromuscular control of the human musculoskeletal system initiates limb movement and results in changes in joint moments, and finally external kinematics and kinetics changes. Previous studies reported the internal joint moments in walking on level surfaces (Cham and Redfern 2002), on inclined surfaces (Redfern and DiPasquale 1997), and during stair ambulation (Salsich et al. 2001). Moreover, some studies were on muscle activity analysis during slip adaptation in walking (Marigold et al. 2003, Marigold and Patla 2002).

A previous part of this study reported the lower extremity kinematics strategies in preventive measures for slips in simulated construction worksite environments (Fong et al. 2005). The purpose of the present study was to investigate musculoskeletal strategies when walking on potential slippery surfaces. The strategies were quantified in terms of internal joint moment and myoelectric responses. The null hypothesis was that there are no changes in internal joint kinetics and myoelectric parameters when walking on surfaces with difference slipperiness. This study would help to add to the knowledge about mechanism of human adaptation to slippery walking surfaces. The findings, together with previous published information, could be used to educate construction 
workers about useful strategies to prevent slips and falls in occupational settings.

\section{Methods}

\subsection{Survey}

Two thousand questionnaires were randomly sent to local construction site workers to obtain statistics about the popular footwear used by workers, the nature of floor surface in construction sites, and the most common type of surface contaminants, in order to better simulate construction site situations. From the results of the survey, the most popular footwear, flooring and contaminant were selected for this study. Sixteen combinations proceeded from two footwear (safety shoe, 94\%; cloth shoe, $2 \%$ ), two surfaces (cement, 57\%; wood, 33\%) and four contaminants (dry; sand, 43\%; water, 39\%; oil, 33\%) were investigated. Despite the cloth shoe was far less popular than the safety shoe, it was also chosen for comparison. A dry surface was also chosen as it represented the safe and non-slippery conditions.

\subsection{Mechanical slip-resistance test}

Slipperiness was quantified by the value of dynamic coefficient of friction (DCOF)

(Hanson et al. 1999, Strandberg 1983). For each of the sixteen 
footwear/flooring/contaminant conditions, DCOF was measured in a mechanical slip-resistance test. A pulley system with adjustable horizontal drag force was used to drag an 11.8-kg-weighted shoe over the testing flooring surface 10 times over a force plate (Kistler 9281CA, Switzerland) (Newton et al. 2002). Figure 1 shows the direction of slide (drag force), the horizontal and vertical reaction forces in the test. The horizontal drag force was increased gradually by adding weights until the shoe slid. DCOF was calculated by dividing the horizontal reaction force by the vertical reaction force. According to the classification scale suggested by Gronqvist et al. (1989), the sixteen conditions were classified into three groups by the measured DCOF (very slip-resistant: DCOF $\geq 0.30$, unsure: $0.15<$ DCOF $<0.19$, slippery: DCOF < 0.14) as shown in Table 1. Later analysis examined the differences between these three groups of different slipperiness.

\subsection{Participant}

Fifteen Chinese males (age $=21.8 \pm 1.3$ years, mass $=64.5 \pm 4.6 \mathrm{~kg}$, height $=1.75 \pm$ $0.06 \mathrm{~m}$ ) with no gait abnormalities, with right leg dominance, and with shoe size 42 (length $=265 \mathrm{~mm}$ ) were recruited for this study. Written informed consent was obtained from all participants before the study. The university ethics committee approved the 
study

\subsection{Instrumentation}

A harness system was installed by attaching a harness (Protecta International AB103, USA) which conformed to the European Safety Standard EN 361 to a horizontal stainless steel wire by means of an adjustable connection lanyard (Protecta International AL110C, USA) and a steel safety hook (Protecta International AJ501, USA) which conformed to the European Safety Standard EN354 and EN362 respectively. The horizontal stainless steel wire was $10 \mathrm{~m}$ in length, and was firmly attached on the wall 2.4 metres from the ground at both ends. Safety shoes which conformed to the European safety standard EN 345 and a cloth sport shoe with size 42 (length $=265 \mathrm{~mm}$ ) were purchased. The shoe sole of the safety shoe fully complied with the main regulations provided by the EEC/89/686 European Directive with harmlessness, comfort, solidity, and protection against skidding risks (UNI 8615/1 - DIN 4843). The cloth sport shoe was made with thin layer of cloth shoe last, and with a thin and flexible rubber shoe sole. A five-metre walking path was prepared by connecting several cement or wooden flooring plates by the university construction work unit. One force plate (Kistler 9281CA, Switzerland) was installed beneath the walking path at the middle position 
(Figure 2). The flooring plate was firmly mounted on top of the force plate by screws. The force plate with mounted top flooring was separated with other flooring plates by small gaps of about five millimetres in width to avoid recording false reaction forces which were out of the force plate areas. The amounts of the contaminants were about 1 $\mathrm{L} / \mathrm{m}^{2}$ for sand, and $0.5 \mathrm{~L} / \mathrm{m}^{2}$ for water and oil, as they could form a thin layer on the flooring surface without spilling off the walking path. The oily condition was prepared with motor oil (Elf 10W40 motor oil) which was often used in engines and machines in construction sites (Cham and Redfern 2001, Lockhart et al. 2003).

\subsection{Procedure}

The harness system was adjusted for each participant so that it would not affect the participant's perceived normal gait, and it could arrest and protect the participant in case of a fall. Participants were requested to dress in tight black short-sleeve t-shirts and shorts provided by the research staff, which together with illuminated silvery reflective skin markers facilitated the auto-digitizing process in video data analysis. Body height and weight were recorded. The reflective skin markers were attached at the major lower extremity anatomical landmarks on right side, including the greater trochanter, lateral femoral condyle, lateral malleolus, fifth metatarsal head and heel (Figure 3). Foot length 
(fifth metatarsal head to lateral malleolus), shank length (lateral malleolus to lateral femoral condyle) and thigh length (lateral femoral condyle to greater trochanter) defined by Winter (1990:56-57) were measured by anthropometer (Holtain-Harpenden, UK) for later inverse dynamics calculation.

Surface electrodes (Medicotest, T-00-S, Denmark) were attached to the skin surface of four selected lower extremity muscles including tibialis anterior, gastrocnemius, rectus femoris and biceps femoris (Marigold and Patla 2002) (Figure 3). Skin surface was shaved to remove hair, lightly abraded and cleaned with alcoholic wipe to facilitate good electrode attachment. Previous studies showed that normalizing the EMG signal to a functional task will have less inter-participant variability compared with normalizing to a maximum voluntary contraction (Branch et al. 1985, Rand and Ohtsuki 2000). Therefore in this study, four standard postures were selected for normalizing purposes. The selected postures for recording normalization signals from biceps femoris, rectus femoris, gastrocnemius, and tibialis anterior were the lower leg raised with included knee joint at 90 degrees, semi-squating with included knee joint at 90 degrees, maximum plantar flexion, and maximum dorsiflexion respectively as shown in Figure 4. Before the experiment, myoelectric signals during submaximal isometric contraction from the four selected postures were recorded. Myoelectric signals were 
collected and amplified by BTS EMG system (Bioengineering Technology \& Systems, Italy).

Each participant was instructed to perform ten trials of walking on each footwear/flooring/contaminant condition in the sequence of dry, sand, water and oil at a self-paced normal speed and to avoid slipping. The walking speed was not controlled but was reported as a dependent variable to reflect the effect of walkway slipperiness on gait strategies. The trial sequence was not randomized so as to avoid the gait alteration effect reported by Cham and Redfern (2002). They found that gait on non-slippery dry walking surface was significantly altered if it was after a trial on a slippery walking surface. The three dimensional reaction forces during right leg stance were recorded by the force plate installed beneath the walking path. A computer was used for data collection. LabVIEW 4.0 (National Instrument, USA) was employed to collect the force plate and myoelectric signals simultaneously. The sampling rate of the analog/digital (A/D) card (National Instrument PCI-6071E, USA) was set at $1000 \mathrm{~Hz}$.

One CCD digital video camera (JVC 9600, Japan) with $50 \mathrm{~Hz}$ filming rate at 1/250s shutter speed was used for videotaping the human motion in sagittal plane. The filmed data were processed by a motion analysis system (Ariel Performance Analysis System, USA) to obtain two-dimensional coordinates and their derivatives of anatomical 
markers. A Pedar insole system (Novel, Germany) was also employed to simultaneously record the position of centre of pressure beneath the foot during stance at $50 \mathrm{~Hz}$ frequency. Synchronization was done by an instant square wave signal to LabVIEW data collection software and a LED light signal to the video camera from a synchronization box, and a flash light signal from the Pedar system to the video camera. Trials with slips were discarded. A slip was defined as when the heel horizontal velocity failed to achieve zero within a three centimetres displacement range (Maynard 2002) immediately after the foot strike (Cham and Redfern 2002), which was checked by motion analysis. The kinematics data obtained from video data and Pedar insole system were used for inverse dynamic calculation.

\subsection{Inverse dynamic calculation}

Two-dimensional joint moments at ankle, knee and hip were calculated by inverse dynamic equations derived by Winter (1990:75-102). The equations were imported to a self-compiled Pascal program (Turbo Pascal for Windows 1.5, Borland International Inc, USA) to calculate the forces and turning moments on the joints in the lower extremities. Anthropometric data including body mass, length of foot, shank and thigh segment were input to the program. From the anthropometric data obtained from cadaver studies 
(Plagenhoef 1983) and summarized by Winter (1990:56-57), segment mass, centre of mass, radius of gyration and moment of inertia of each segment were calculated. Kinematics data were input for the calculation. These data included the two-dimensional coordinates of ankle, knee, hip, coordinates, linear and angular acceleration of foot, shank and thigh segment. Kinetics data including horizontal and vertical ground reaction forces from force plate, and the centre of pressure position from Pedar insole system were also imported. From the anthropometric data and the synchronized kinematics and kinetics data, internal joint moments were calculated. Joint moment data were magnitude-normalized to body mass $(\mathrm{Nm} / \mathrm{kg})$ and were time-normalized to 0-100\% stance.

\subsection{Electromyography signal processing}

Myoelectric signals from each muscle channel from each trial were magnitude normalized to the maximum signal magnitude in the submaximal isometric contraction tests. They were then time-normalized and trimmed into four phases, I - from touchdown to mid-stance (early stance), II - from mid-stance to take-off (late stance), III - from take-off to mid-swing (early swing), and IV - from mid-swing to the next touchdown (late swing). Each trimmed signal was time-normalized to $0-100 \%$ stance or 
swing phase, and was band-pass filtered by a $12^{\text {th }}$ order finite impulse response filter equation from $20-500 \mathrm{~Hz}$ with an $80 \mathrm{~dB}$ out of band signal rejection. The filtered signal was then full-wave rectified, and the root mean square (RMS) of the signal at each channel in each stride phase was calculated (Cook 1992). The EMG signal for one stride was also processed to yield the linear envelope for graphical presentation of the EMG profile at each channel.

\subsection{Data analysis}

Both joint moment and myoelectric data of the successful trials of walking without slips were averaged for each footwear/flooring/contaminant condition for comparison between groups with different slipping potential. Joint moment data were extracted for every $10 \%$ stance interval from $0 \%$ stance to mid-stance. One-way multivariate analysis of variance (MANOVA) with repeated measures was employed to examine the difference in joint moment and myoelectric response between the classified slip resistant groups. One-way analysis of variance (ANOVA) was employed to examine the difference in each joint moment at selected time points and myoelectric parameter in each stride phase between groups. The significance level was set at $\mathrm{p}<.05$ level. Tukey post-hoc pairwise comparisons were conducted between each pair of groups when 
significant differences reached a $\mathrm{p}<.01$ significance level.

\section{Results}

\subsection{Internal joint moments}

The trend profiles of joint moments from foot strike to foot take-off are shown in Figure

5. The descriptive statistics and the results of ANOVA and Tukey tests are shown in

Table 2. In slip-resistant condition, ankle plantar flexion moment occurred immediately after foot strike until about 3\% stance, followed by rapid dorsiflexion moment reaching a local maximum of about $0.4 \mathrm{Nm} / \mathrm{kg}$ at about $22 \%$ stance and end at about $48 \%$ stance. Plantar flexion moment then occurred again and reached a maximum of $0.2 \mathrm{Nm} / \mathrm{kg}$ at about $70 \%$ stance and ended at about $85 \%$ stance, followed by dorsiflexion moment until foot take-off. The trend for the unsure condition showed a similar pattern and magnitude with an earlier occurrence of the second plantar flexion moment at about 41\% stance. For slippery condition, ankle plantar flexion moment occurred for a slightly longer duration right after foot strike until about 5\% stance, followed by a mild dorsiflexion moment reaching only about $0.08 \mathrm{Nm} / \mathrm{kg}$ at about $13 \%$ stance and ended at $25 \%$ stance. Then a prolonged and forceful plantar flexion moment reaching $0.7 \mathrm{Nm} / \mathrm{kg}$ occurred from $25 \%$ to $92 \%$ stance, followed by a slight dorsiflexion moment until foot 
take-off.

MANOVA showed that the internal joint moment parameters were significantly affected by the walking surface slipperiness $(\mathrm{p}<.01)$. At ankle joint, ANOVA showed that significant differences were found at 30\%, 40\% and 50\% stance $(\mathrm{p}<.01)$. Tukey pairwise comparison showed that the significant difference was between the resistant-slippery and unsure-slippery pairs $(\mathrm{p}<.05)$. No significant differences were found between the resistant and unsure groups from foot strike to mid-stance at each selected time point.

At the knee joint, for the slip-resistant condition, knee flexion occurred at the first 5\% stance, followed by a biphasic knee extension reaching local maximums of about $0.9 \mathrm{Nm} / \mathrm{kg}$ at $20 \%$ stance and $2 \mathrm{Nm} / \mathrm{kg}$ at $80 \%$ stance. The unsure condition showed similar trend with a slightly delayed first local peak of about $0.9 \mathrm{Nm} / \mathrm{kg}$ at about $30 \%$ stance, and with a slightly higher second peak of about $2.1 \mathrm{Nm} / \mathrm{kg}$ at $80 \%$ stance. No significant differences were found from foot strike to mid-stance. The slippery condition showed a similar trend also but without the first local peak. This also reached its maximum of about $1.8 \mathrm{Nm} / \mathrm{kg}$ at about $80 \%$ stance. ANOVA showed than significant differences were found at 10\%, 20\%, and 30\% ( $<<.01)$. Tukey pairwise comparison showed that the significant differences were between resistant-unsure $(\mathrm{p}<.05)$ and 
resistant-slippery conditions $(\mathrm{p}<.01)$ at $10 \%$ stance, and between resistant-slippery ( $\mathrm{p}$ $<.01)$ and unsure-slippery conditions ( $\mathrm{p}<.01)$ at $20 \%$ and $30 \%$.

At the hip joint, for slip-resistant condition, hip extension occurred at the first 8\% stance, reaching a maximum hip extension moment of about $0.5 \mathrm{Nm} / \mathrm{kg}$. Then a biphasic hip flexion with first local maximum of about $0.6 \mathrm{Nm} / \mathrm{kg}$ at $15 \%$ stance and the second local maximum of about $1.2 \mathrm{Nm} / \mathrm{kg}$ at $80 \%$ stance occurred. For the unsure condition, a similar trend was found, with the first hip extension period occurring at about $11 \%$ stance, with the first local maximum hip flexion moment of about $0.6 \mathrm{Nm} / \mathrm{kg}$ occurred at about 30\% stance, and with the second flexion moment peak of about 1.3 $\mathrm{Nm} / \mathrm{kg}$ at about $80 \%$ stance. For slippery condition, similar trend with the absence of the first local maximum hip flexion was found. Hip extension occurred immediately at foot strike until about $19 \%$ stance, followed by a hip flexion reaching its maximum at about $1.2 \mathrm{Nm} / \mathrm{kg}$ at $80 \%$ stance. ANOVA showed no significant differences at the $\mathrm{p}$ $<.01$ level.

\subsection{Electromyography}

The trend profiles of the processed EMG signal for one whole stride displayed in phases are shown in Figure 6. The descriptive statistics and the results of ANOVA and Tukey 
pairwise comparison are shown in Table 3. The initial value of EMG signal of tibialis anterior at foot strike was about $5 \%$ of the signal collected in the submaximal isometric contraction test. The muscle activity dropped quickly to about $1.7 \%$ during early stance (phase I). In late stance (phase II) the level increased a little bit and reached $2 \%$ at the mid late stance, and then dropped to about $1 \%$ and rose again to reach $2.2 \%$ finally at foot take-off. In early swing, tibialis anterior was most active compared in other phases. It reached up to $3.2 \%$ at mid early swing and dropped to about $2 \%$ at mid-swing. The muscle activity then increased gradually from $2 \%$ to about $5 \%$ to the next stride. Unsure and slippery conditions both showed similar trends with a slightly higher EMG signal during stance phases. Gastrocnemius activity increased gradually in the early stance (phase I) from $1.7 \%$ to $4 \%$ in mid-stance. The muscle activity then increased rapidly to $10 \%$ at mid-late stance, and then dropped to about $1 \%$ at foot take-off. The muscle activity then remained at a rather stable level during the swing phase (phase III and IV). Again, the unsure condition showed similar trend, but with a generally higher activity in early stance. For the slippery condition, the muscle activity showed less fluctuation. It started at about $2.1 \%$ at foot strike and increased gradually to only about $6 \%$ in mid-late stance, but also dropped less rapidly and finally reached $2 \%$ at foot take-off. It then also remained in a rather stable level at about $2 \%$ and increased a little bit at the end of 
swing phase to prepare foot strike.

For rectus femoris, the muscle activity started at about $5.6 \%$ at the foot strike, then dropped gradually to about $2 \%$ at mid-stance and finally at about $1.2 \%$ at foot take-off. The activity remained at $1.2 \%$ in the early swing (phase III) and increased gradually after the mid-late swing. The unsure condition showed a similar trend with generally higher muscle activity throughout the gait cycle, and with greater fluctuation in late stance (phase II). Slippery conditions showed a different trend. It started in a lower muscle activity level (about 4.1\%) and dropped gradually until mid-stance. It then increased and reached a local maximum at the mid-late stance with a magnitude of about $4.2 \%$ and dropped again to about $2 \%$ at foot take-off. It then remained at a quite stable level and finally increased again to 3\%. Biceps femoris activity started at about $10 \%$ and dropped rapidly to a level of about 3\% and became steady until mid-swing. It then increased quickly to about $15 \%$ in mid-late swing and dropped to about $12 \%$ at the next foot strike. The unsure condition showed a similar trend but with less rapid increase in phase IV. The slippery condition showed a similar trend with less fluctuation, with a less rapid drop in phase I and with a less rapid rise in phase IV.

MANOVA showed that muscle activities represented by root mean square values (RMS) at each muscle channel at each stride phase were significantly affected by the 
walking surface slipperiness $(\mathrm{p}<.01)$. For gastrocnemius, ANOVA tests showed significant differences in both the early and late swing phases $(\mathrm{p}<.01)$. Tukey tests showed that the significant differences were between resistant-unsure conditions in phase III $(\mathrm{p}<.01)$ and between resistant-unsure and resistant-slippery conditions in phase IV $(\mathrm{p}<.01)$. For rectus femoris, ANOVA showed significant differences in phase II $(\mathrm{p}<.01)$. Tukey tests showed than the difference were between all the three pairs of condition $(\mathrm{p}<.05)$. No significant differences between the three groups were found in tibialis anterior and biceps femoris.

\section{Discussion}

One limitation in this study is the effect of harnessed walking. The harness must be employed in this study as in numerous similar studies (Cham and Redfern 2001, Cham and Redfern 2002, Hanson et al. 1999, Lockhart et al. 2003, Marigold et al. 2003, Marigold and Patla 2002, Myung and Smith 1997) to ensure the safety of the participant and to fulfill the requirement of the ethics approval. The effects on gait changes may be questioned by some readers. Some researchers doing similar studies have claimed that the safety harness system in no way interfered with the participants' behaviour and response during the walking tasks (Maynard 2002). However, as no trials can be done 
without harness in this study, the effect on gait cannot be demonstrated. In order to minimize this effect, the harness was adjusted every time for each participant so that it could prevent the participant hitting the ground and at the same time it would not affect the participant's perceived normal gait as verbally reported by them. The authors assume that the effect of the harness on walking was minimized by the research team's maximum effort.

In studies involving human locomotion, the propagation speed is often controlled by treadmill (Hong and Brueggemann 2000), or by other measures. However the methods of speed controlling are not always well reported, or even not reported at all. This may be a result of a lack of good methodology to effectively control the propagation speed in similar studies, especially in those in which treadmill is not applicable in the study protocol. In numerous studies, the participants were instructed to walk at their natural or comfortable speed (Cham and Redfern 2001, Cham and Redfern 2002, Hanson et al. 1999, Lockhart et al. 2003, Myung and Smith 1997). In this study, the authors believe that controlling the walking speed for gait on slippery surfaces is not realistic. People tend to walk slower on slippery surface, except in the unexpected case. Due to these reasons, the walking speed in this study was not controlled, but was recorded. It has been reported with other kinematics findings in a previous study (Fong 
et al. 2005).

The sequence of surface contaminants was not randomized. This was to prevent the gait anticipation effect. Cham and Redfern (2002) conducted a study with the sequence of dry, anticipation and recovery. In the dry trials, participants knew that the floor was dry and safe. In the anticipation trials, participants were uncertain about the contaminant conditions, and therefore demonstrated various strategies and finally reduced the required friction to propagate to avoid slip. In the recovery trials after the contaminated trial, participants again knew the floor was dry and safe. However, significant gait changes were observed. Therefore, to avoid this gait anticipation effect, the sequence was designed in an order with increasing slipping potential but not randomized.

Trials were not blinded to the participants in this study. Cham and Redfern (2001) conducted another study investigating the corrective reactions to unexpected slip events. In order to ensure unexpected situations, the participants were blind to the experimental trials. The blinding method was done by playing loud music to distract the participant, and dimming the light to prevent the participants identifying the contaminant conditions. Participants followed guiding lights at both side of the walkway and walked in a dark environment with no knowledge of the slipping potential of the surface. The body kinematics before stepping on the slippery surface were found to be similar, indicating 
that the blinding protocol was successful in preventing prior knowledge of contaminant conditions. Marigold and Patla (2002) investigated the effects of prior experience and knowledge on strategies for dynamic stability during gait on slippery surfaces. The blinding method was done by having the participants step on a set of steel rollers mounted on a frame on top of a force plate that could be locked or unlocked. The rollers provided a DCOF of 0.03 , which was considered to be "very slippery” by Gronqvist’s classification scale (Gronqvist et al. 1989). A slip was provided in anterior-posterior direction when unlocked. However, the scope of this study was different. The present authors aimed to measure the preventive strategies of humans on expected slippery surfaces. Participants should have prior knowledge about the floor conditions. Therefore, blinding trials are not applicable in this study.

Trials with slips were discarded. This was because the biomechanics in the recovery action after a slip was not the main purpose of this study. The authors agree that an unexpected condition is a major factor in subsequent slips and falls. However, such a factor has already been studied by others in similar research fields (Cham and Redfern 2001, Marigold et al. 2003). To know more about the prevention of slipping, researchers should work on different, but related topics. Therefore this study focused on preventive strategies only. 
The results of joint moments were in agreement with some previous studies which indicated that in normal walking on slip-resistant surfaces, moments at the ankle, knee and hip were found to be plantar flexion, extension and flexion respectively (Cham and Redfern 2002, Redfern and DiPasquale 1997). The results revealed that in adaptation to slippery walking surfaces, ankle joints tended toward plantar flexion moment during most of the stance time. The occurrence of the plantar flexion moment immediately after foot strike was in agreement with the results showing flat foot landing in a previously published study (Fong et al. 2005). Knee extension and hip flexion occurred in most of the stance time for all three groups. However, in the slippery condition, there were less rapid knee extension and hip flexion with the absence of the first local maximum of the biphasic movement. Statistical analysis suggested that the knee joint played an important role in adjusting to a slippery surface from the $10 \%$ - $30 \%$ stance, and the ankle joint from the $30 \%$ stance to mid-stance.

The knee had less extension moment during the early stance. This may help put the lower limb in a slightly flexed, but not fully extended orientation. The authors believe that when the leg is in a fully extended situation, it will be difficult for a recovery action in case of a slip. Therefore putting the leg in a slightly flexed position may be a strategy to prepare for corrective reactions to regain balance when walking on slippery surfaces. 
The ankle showed significantly more plantarflexion moment from 30\% to mid-stance. This may help in applying a propulsive force which has more vertical component to the ground. If the vertical component increases, more frictional force will be available for propulsion to the next step. A previous study investigating the joint moments in recovery action after slip showed that the ankle did not show significant changes, and the knee and hip joint evoked significant flexion and extension moments respectively (Cham and Redfern 2001). These studies showed that preventive measures for slips involved ankle and knee joint moment instead. The results of this study, together with those of published studies, suggest that in safe walking on slippery surfaces, one may need to have good ability for neuromuscular coordination of all three lower extremity joints in order to adapt well to the slippery surface and to recover if a slip occurs.

The profile of myoelectric signals for the four tested muscles showed that each of them was active in different phases of a stride cycle. Rectus femoris and gastrocnemius are lower extremity extensors and they were active mainly in stance phase. Tibialis anterior and biceps femoris are flexors and they were active in swing phase. Rectus femoris was found to be more active in late stance in slippery conditions. Gastrocnemius was more active in the whole swing phase. While the extensors showed increased activity, the activity of the flexors did not significantly vary. This may result 
in isometric contraction and help to keep the lower leg stiff. Moreover, the overall maximum muscle activity during walking was far lower (about 15\%) from the submaximal isometric contraction tasks for normalization purposes. The authors believe that the joint torque magnitudes are also far below the capability limits. This may suggest that slips and falls are not caused by muscle strength weakness, but neuromuscular coordination failure.

This study adds knowledge to the previous published studies by reporting the musculoskeletal strategies in terms of joint moments and myoelectric changes during human preventive measures for slips. Further studies should investigate the role of the upper extremity as well as the mechanism of neuromuscular control in maintaining balance on slippery walking surfaces. Other environments which lead to significant slips and falls hazards are also possible investigation targets. Walking with loads in simulated construction sites are suggested for investigation because carrying loads is very common in these worksites. Moreover, carrying loads may lead to inferior vision, shifted centre of mass, limited limb motion, and finally diminished adaptation ability.

\section{Conclusion}

On slippery walking surfaces, human can adapt and walk without slips by using 
musculoskeletal strategies. Such strategies included significant increased muscle activity of gastrocnemius in the swing phase, and in rectus femoris in the late stance phase. Within the early stance phase, changes in joint moments included more ankle plantar flexion moment from 30\% stance to mid-stance, and less knee extension strategies from $10 \%$ to $30 \%$ stance.

Further studies should involve upper extremity neuromuscular coordination, as well as different environmental and human factors which lead to slips and falls hazards. Future focus should also be on neuromuscular coordination training in order to successfully prevent slips and falls events.

\section{Acknowledgement}

This study was financially supported by the Hong Kong Occupational Safety and Health Council. The support of the Hong Kong Construction Industry Employees General Union to conduct the survey is acknowledged. The paper's contents are solely the responsibility of the authors and not necessarily represent the official view of the Hong Kong Occupational Safety and Health Council and the Hong Kong Construction Industry Employees General Union. 


\section{References}

Bentley, T. A. AND Haslam, R. A. 1998, Slip, trip and fall accidents occurring during the delivery of mail. Ergonomics 41, 1859-1872.

Branch, T. P., Hunter, R. AND Donath, M. 1985, Dynamic EMG analysis of anterior cruciate deficient legs with and without bracing during cutting. American Journal of Sports Medicine 17, 35-41.

CHAM, R. AND REDFERN, M. S. 2001, Lower extremity corrective reactions to slip events. Journal of Biomechanics 34, 1439-1445.

CHAM, R. AND REDFERN, M. S. 2002, Changes in gait when anticipating slippery floors. Gait and Posture 15, 159-171.

CoOK, T. 1992, EMG comparison of lateral step-up and stepping machine exercise. Journal of Orthopaedic and Sports Physical Therapy 16, 108-113.

FonG, D. T. P., Hong, Y. AND LI, J. X. 2005, Lower extremity gait kinematics on slippery surfaces in construction worksites. Medicine and Science in Sports and Exercise 37, 447-454.

GRONQVIST, R. AND RoINE, J., 1993, Serious occupational accidents caused by slipping. In Advances in Industrial Ergonomics and Safety V, R. NIELSEN AND K. JoRGENSEN (Eds.) (London: Taylor \& Francis), pp. 515-519.

Gronqvist, R., Roine, J., JARVinen, E. AND Korhonen, E. 1989, An apparatus and a method for determining the slip resistance of shoes and floors by simulation of human foot motions. Ergonomics 32, 979-995.

Hanson, J. P., REDFERn, M. S. And MaZumdar, M. 1999, Predicting slips and falls considering required and available friction. Ergonomics 42, 1619-1633.

Hong, Y. AND BRueggemann, G. P. 2000, Changes in gait patterns in 10-year-old boys 
with increasing loads when walking on a treadmill. Gait and Posture 11, 254-259.

Hong Kong Occupational Safety And Health Council, 2003, Statistics on occupational injuries compiled by the Labour Department of the Government of the Hong Kong Special Administrative Region, 15-17.

Kadaba, M. P., Wootten, M. E., Gainey, J. And Cochran, G. V. 1985, Repeatability of phasic muscle activity: performance of surface and intramuscular wire electrodes in gait analysis. Journal of Orthopaedic Research 3, 350-359.

LerouX, A., Fung, J. AND BARBEAU, H. 2002, Postural adaptation to walking on inclined surfaces: I. normal strategies. Gait and Posture 15, 64-74.

LOCKHART, T. E., WOLDSTAD, J. C. AND SMITH, J. L. 2003, Effects of age-related gait changes on the biomechanics of slips and falls. Ergonomics 36, 1136-1160.

Manning, D. P., Ayers, I., Jones, C., Bruce, M. And Cohen, K. 1988, The incidence of underfoot accidents during 1985 in a working population of 10,000 Merseyside people. Journal of Occupational Accidents 10, 121-130.

Marigold, D. S., Bethune, A. J. And Patla, A. E. 2003, Role of the unperturbed limb and arms in the reactive recovery response to an unexpected slip during locomotion. Journal of Neurophysiology 89, 1727-1737.

MARIGOLD, D. S. AND PATLA, A. E. 2002, Strategies for dynamic stability during locomotion on a slippery surface: effects of prior experience and knowledge. Journal of Neurophysiology 88, 339-353.

MAYNARD, W. S. 2002, Tribology: preventing slips and falls in the workplace. Occupational Health and Safety 71, 134-140.

MyUNG, R. AND SMITH, J. L. 1997, The effect of load carrying and floor contaminants on slip and fall parameters. Ergonomics 40, 235-246. 
Newton, R., Doan, B., Meese, M., Conroy, B., Black, K., Sebstianelli, W. And KRAMER, W. 2002, Interaction of wrestling shoe and competition surface: effects on coefficient of friction with implications for injury. Sports Biomechanics 1, 157-166.

Plagenhoef, S. 1983, Anatomical data for analyzing human motion. Research Quarterly for Exercise and Sport 54, 169-178.

RAND, M. K. AND OHTSUKI, T. 2000, EMG analysis of lower limb muscles in humans during quick change in running directions. Gait and Posture 12, 169-183.

REDFERN, M. S. AND DiPASQUALE, J. D. 1997, Biomechanics of descending ramps. Gait and Posture 6, 119-125.

SAlsich, G. B., Brechter, J. H. AND Powers, C. M. 2001, Lower extremity kinetics during stair ambulation in patients with and without latellofemoral pain. Clinical Biomechanics 16, 906-912.

STRANDBERG, L. 1983, On accident analysis and slip-resistance measurement. Ergonomics 26, 11-32.

United States Department of LABOr, Bureau of LABOR Statistics, 1996, Lost-worktime injuries and illnesses: characteristics and resulting time away from work, 98-157.

Winter, D. A. 1990, Biomechanics and Motor Control of Human Movement, (2nd edn). New York: Wiley. 
Table 1 - Slip classes of the sixteen conditions

\begin{tabular}{lllll}
\hline Flooring & Contaminant & Footwear & DCOF & Class \\
\hline Wood & Dry & Safety shoe & $\geq 0.30$ & Very slip-resistant \\
& & Cloth shoe & $\geq 0.30$ & Very slip-resistant \\
& Sand & Safety shoe & $\geq 0.30$ & Very slip-resistant \\
& Water & Cloth shoe & $\geq 0.30$ & Very slip-resistant \\
& Safety shoe & $\geq 0.30$ & Very slip-resistant \\
& Oil & Cloth shoe & $\geq 0.30$ & Very slip-resistant \\
& & Safety shoe & $0.15-0.19$ & Unsure \\
& Dry & Cloth shoe & $<0.14$ & Slippery \\
& & Safety shoe & $\geq 0.30$ & Very slip-resistant \\
& Sand & Cloth shoe & $\geq 0.30$ & Very slip-resistant \\
& & Safety shoe & $\geq 0.30$ & Very slip-resistant \\
& Water & Cloth shoe & $\geq 0.30$ & Very slip-resistant \\
& & Safety shoe & $\geq 0.30$ & Very slip-resistant \\
& Oil & Cloth shoe & $\geq 0.30$ & Very slip-resistant \\
& & Safety shoe & $\geq 0.30$ & Very slip-resistant \\
& & Cloth shoe & $\geq 0.30$ & Very slip-resistant \\
\hline
\end{tabular}

DCOF: Dynamic coefficient of friction 
Table 2 - Descriptive statistics, results of ANOVA and Tukey tests of internal joint moment parameters

\begin{tabular}{|c|c|c|c|c|}
\hline \multirow{2}{*}{$\begin{array}{l}\text { Internal joint moment parameters } \\
\text { (Normalized to body mass) }\end{array}$} & \multicolumn{3}{|l|}{ Mean (SD) } & \multirow{2}{*}{$\begin{array}{l}\text { Statistical analysis p-value }{ }^{\mathrm{a}} \\
\text { Tukey }^{\mathrm{b}}\end{array}$} \\
\hline & Very slip-resistant & Unsure & Slippery & \\
\hline Ankle moment, foot strike (Nm/kg) & $-.027(.037)$ & $-.004(.014)$ & $-.018(.028)$ & No significant differences \\
\hline Ankle moment, $10 \%$ stance $(\mathrm{Nm} / \mathrm{kg})$ & $.203(.150)$ & $.184(.112)$ & $.063(.143)$ & No significant differences \\
\hline Ankle moment, $20 \%$ stance $(\mathrm{Nm} / \mathrm{kg})$ & $.373(.281)$ & $.321(.229)$ & $.032(.216)$ & $<.05 /$ not performed \\
\hline Ankle moment, $30 \%$ stance $(\mathrm{Nm} / \mathrm{kg})$ & $.312(.300)$ & $.235(.246)$ & $-.107(.218)$ & $<.01 /(\mathrm{R}-\mathrm{S})^{* *},(\mathrm{U}-\mathrm{S})^{*}$ \\
\hline Ankle moment, $40 \%$ stance $(\mathrm{Nm} / \mathrm{kg})$ & $.138(.297)$ & $.024(.220)$ & $-.340(.219)$ & $<.01 /(\mathrm{R}-\mathrm{S})^{* *},(\mathrm{U}-\mathrm{S})^{*}$ \\
\hline Ankle moment, $50 \%$ stance $(\mathrm{Nm} / \mathrm{kg})$ & $-.017(.295)$ & $-.158(.171)$ & $-.555(.206)$ & $<.01 /(\mathrm{R}-\mathrm{S})^{*},(\mathrm{U}-\mathrm{S})^{*}$ \\
\hline Knee moment, foot strike (Nm/kg) & $-.133(.149)$ & $-.056(.052)$ & $-.060(.047)$ & No significant differences \\
\hline Knee moment, $10 \%$ stance $(\mathrm{Nm} / \mathrm{kg})$ & $.409(.195)$ & $.257(.079)$ & $.113(.090)$ & $<.01 /(\mathrm{R}-\mathrm{U})^{*},(\mathrm{R}-\mathrm{S})^{* *}$ \\
\hline Knee moment, $20 \%$ stance $(\mathrm{Nm} / \mathrm{kg})$ & $.851(.256)$ & $.749(.163)$ & $.328(.136)$ & $<.01 /(\mathrm{R}-\mathrm{S})^{* *},(\mathrm{U}-\mathrm{S})^{* *}$ \\
\hline Knee moment, 30\% stance $(\mathrm{Nm} / \mathrm{kg})$ & $.873(.223)$ & $.892(.218)$ & $.541(.136)$ & $<.01 /(\mathrm{R}-\mathrm{S})^{* *},(\mathrm{U}-\mathrm{S})^{* *}$ \\
\hline Knee moment, $40 \%$ stance $(\mathrm{Nm} / \mathrm{kg})$ & $.861(.194)$ & $.870(.215)$ & $629(.159)$ & $<.05 /$ not performed \\
\hline Knee moment, 50\% stance (Nm/kg) & $1.031(.215)$ & $.990(.140)$ & $.777(.142)$ & $<.05 /$ not performed \\
\hline Hip moment, foot strike (Nm/kg) & $-.241(.360)$ & $-.058(.103)$ & $-.056(.086)$ & No significant differences \\
\hline Hip moment, $10 \%$ stance $(\mathrm{Nm} / \mathrm{kg})$ & $.148(.406)$ & $-.056(.136)$ & $-.139(.063)$ & No significant differences \\
\hline Hip moment, 20\% stance (Nm/kg) & $.528(.407)$ & $.446(.244)$ & $.040(.159)$ & $<.05 /$ not performed \\
\hline Hip moment, 30\% stance (Nm/kg) & $.513(.291)$ & $.574(.160)$ & $.289(.150)$ & No significant differences \\
\hline Hip moment, $40 \%$ stance (Nm/kg) & $.513(.240)$ & $.593(.126)$ & $.435(.121)$ & No significant differences \\
\hline Hip moment, 50\% stance (Nm/kg) & $.631(.252)$ & $695(.134)$ & $.571(.120)$ & No significant differences \\
\hline
\end{tabular}

R - Very slip-resistant, U - Unsure, S - Slippery

${ }^{a}$ ANOVA test of the three classes.

${ }^{\mathrm{b}}$ Results of Tukey test showed significant difference between groups $-{ }^{* *} \mathrm{p}<.01,{ }^{*} \mathrm{p}<.05$. 
Table 3 - Descriptive statistics, results of ANOVA and Tukey tests of muscle activity parameters (RMS)

\begin{tabular}{|c|c|c|c|c|}
\hline \multirow{2}{*}{$\begin{array}{l}\text { Muscle activity parameters (RMS) } \\
\text { (Magnitude normalized, \%) }\end{array}$} & \multicolumn{3}{|l|}{ Mean (SD) } & \multirow[t]{2}{*}{ Statistical analysis p-value ${ }^{\mathrm{a}} /$ Tukey $^{\mathrm{b}}$} \\
\hline & Very slip-resistant & Unsure & Slippery & \\
\hline Tibialis anterior, Phase I & $1.978(.917)$ & $2.391(1.994)$ & $2.590(2.087)$ & No significant differences \\
\hline Tibialis anterior, Phase II & $1.370(.783)$ & $1.883(2.232)$ & $2.115(1.892)$ & No significant differences \\
\hline Tibialis anterior, Phase III & $.659(.356)$ & $.589(.310)$ & $.742(.461)$ & No significant differences \\
\hline Tibialis anterior, Phase IV & $.740(.376)$ & $.636(.306)$ & $.650(.399)$ & No significant differences \\
\hline Gastrocnemius, Phase I & $1.958(.799)$ & $2.510(1.363)$ & $2.827(1.334)$ & No significant differences \\
\hline Gastrocnemius, Phase II & $4.046(1.735)$ & $4.238(1.816)$ & $4.034(1.853)$ & No significant differences \\
\hline Gastrocnemius, Phase III & $.259(.079)$ & $.340(.180)$ & $.346(.197)$ & $<.01 /(\mathrm{R}-\mathrm{U})^{* *}$ \\
\hline Gastrocnemius, Phase IV & $.292(.099)$ & $.414(.218)$ & $.496(.381)$ & $<.01 /(\mathrm{R}-\mathrm{U})^{* *},(\mathrm{R}-\mathrm{S})^{* *}$ \\
\hline Rectus femoris, Phase I & $2.518(1.399)$ & $2.905(1.265)$ & $3.144(1.386)$ & No significant differences \\
\hline Rectus femoris, Phase II & $1.108(.543)$ & $1.705(.621)$ & $3.239(2.102)$ & $<.01 /(\mathrm{R}-\mathrm{U})^{*},(\mathrm{R}-\mathrm{S})^{* *},(\mathrm{U}-\mathrm{S})^{* *}$ \\
\hline Rectus femoris, Phase III & $.274(.103)$ & $.326(.099)$ & $.466(.457)$ & $<.05 /$ not performed \\
\hline Rectus femoris, Phase IV & $.574(.225)$ & $.652(.236)$ & $.728(.334)$ & $<.05 /$ not performed \\
\hline Biceps femoris, Phase I & 4.333 (3.991) & $4.543(2.720)$ & $7.399(5.610)$ & No significant differences \\
\hline Biceps femoris, Phase II & $2.185(2.051)$ & $2.328(1.501)$ & $3.240(2.643)$ & No significant differences \\
\hline Biceps femoris, Phase III & $.593(.402)$ & $.624(.446)$ & $.846(.732)$ & No significant differences \\
\hline Biceps femoris, Phase IV & $3.117(2.454)$ & $2.518(1.428)$ & $2.074(1.85)$ & No significant differences \\
\hline
\end{tabular}

Phase I - early stance; Phase II - late stance; Phase III - early swing; Phase IV - late swing. R - Very slip-resistant, U - Unsure, S - Slippery

${ }^{a}$ ANOVA test of the three classes.

${ }^{\mathrm{b}}$ Results of Tukey test showed significant difference between groups $-{ }^{* *} \mathrm{p}<.01,{ }^{*} \mathrm{p}<.05$. 


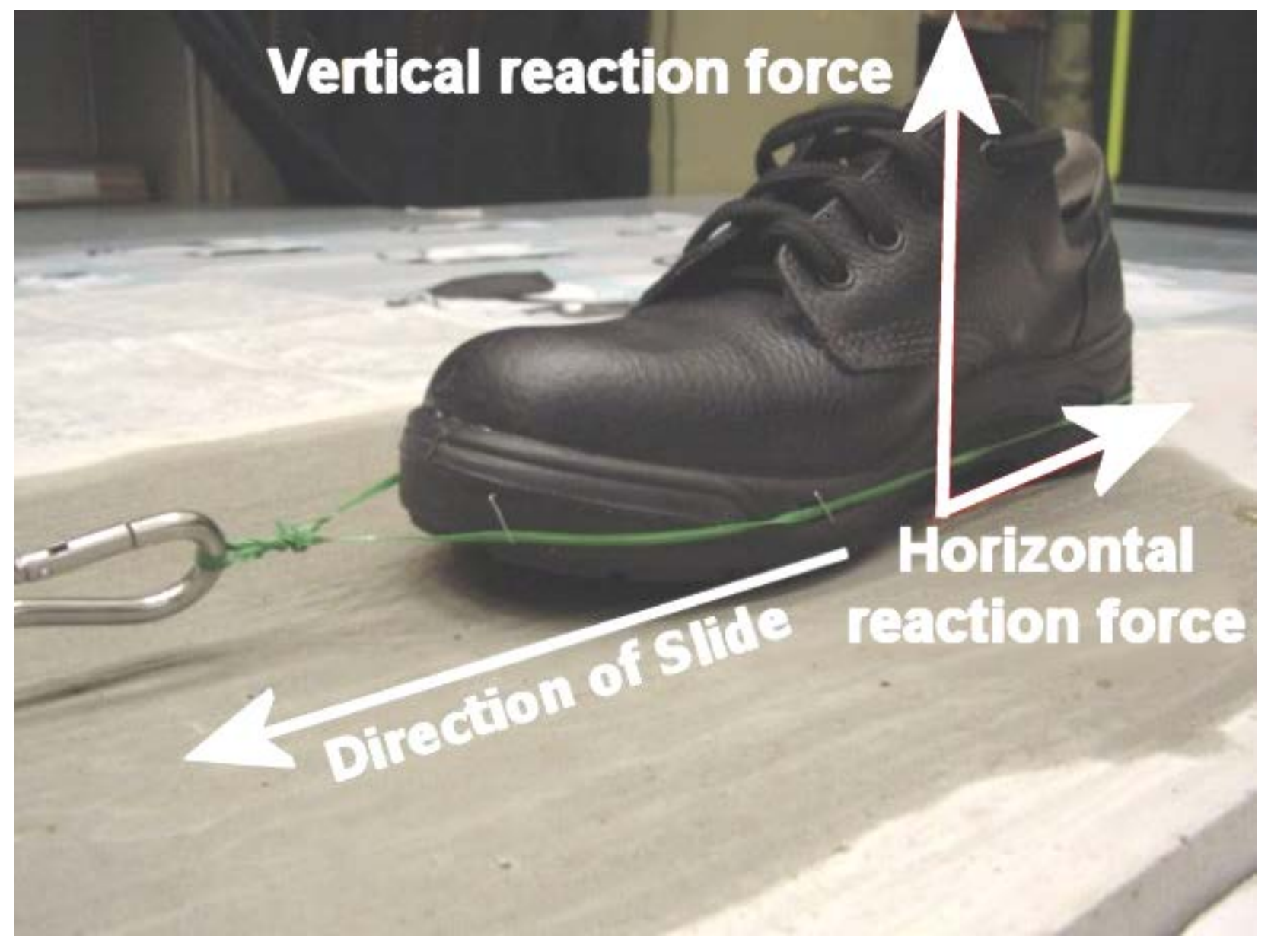

Figure 1 - Direction of slide, horizontal and vertical reaction force in mechanical slip-resistance test. 


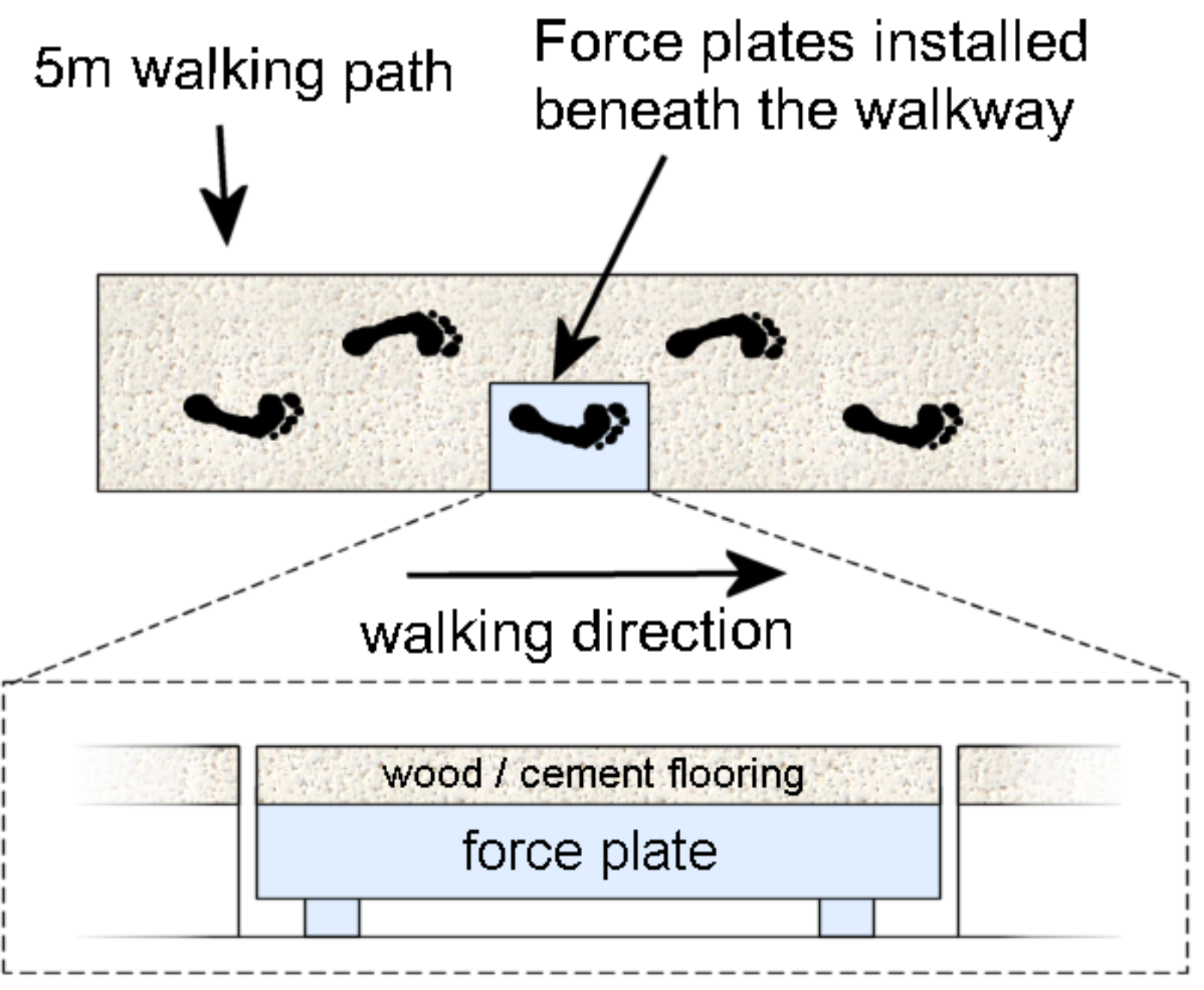

Figure 2 - Walkway design with force plates installed beneath. 


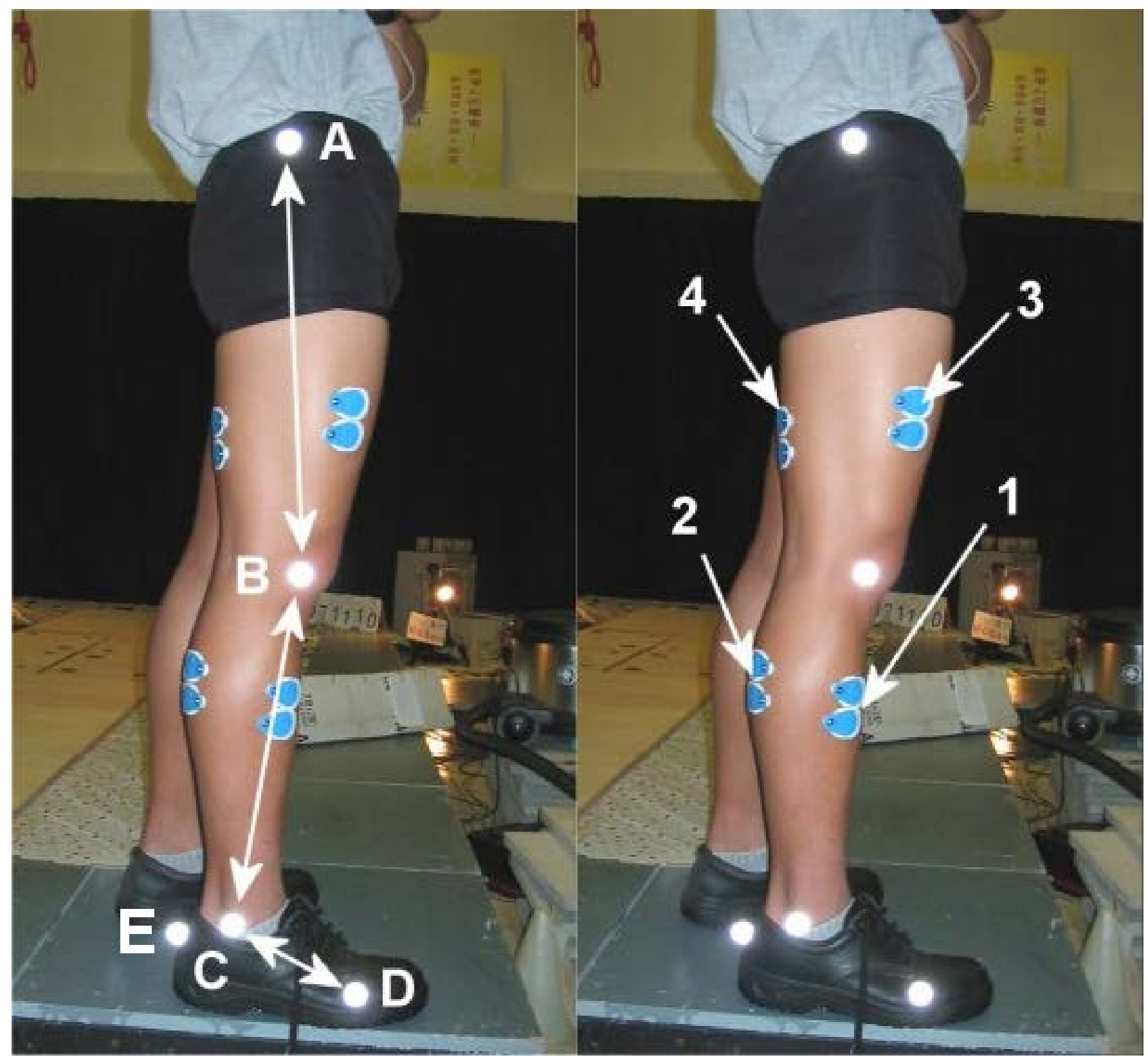

Figure 3 - Marker positions (A - greater trochanter, B - lateral femoral condyle, C - lateral malleolus, D - fifth metatarsal head, E - heel) and electrode positions (1 - tibialis anterior, 2 - gastrocnemius, 3 rectus femoris, 4 - biceps femoris). 


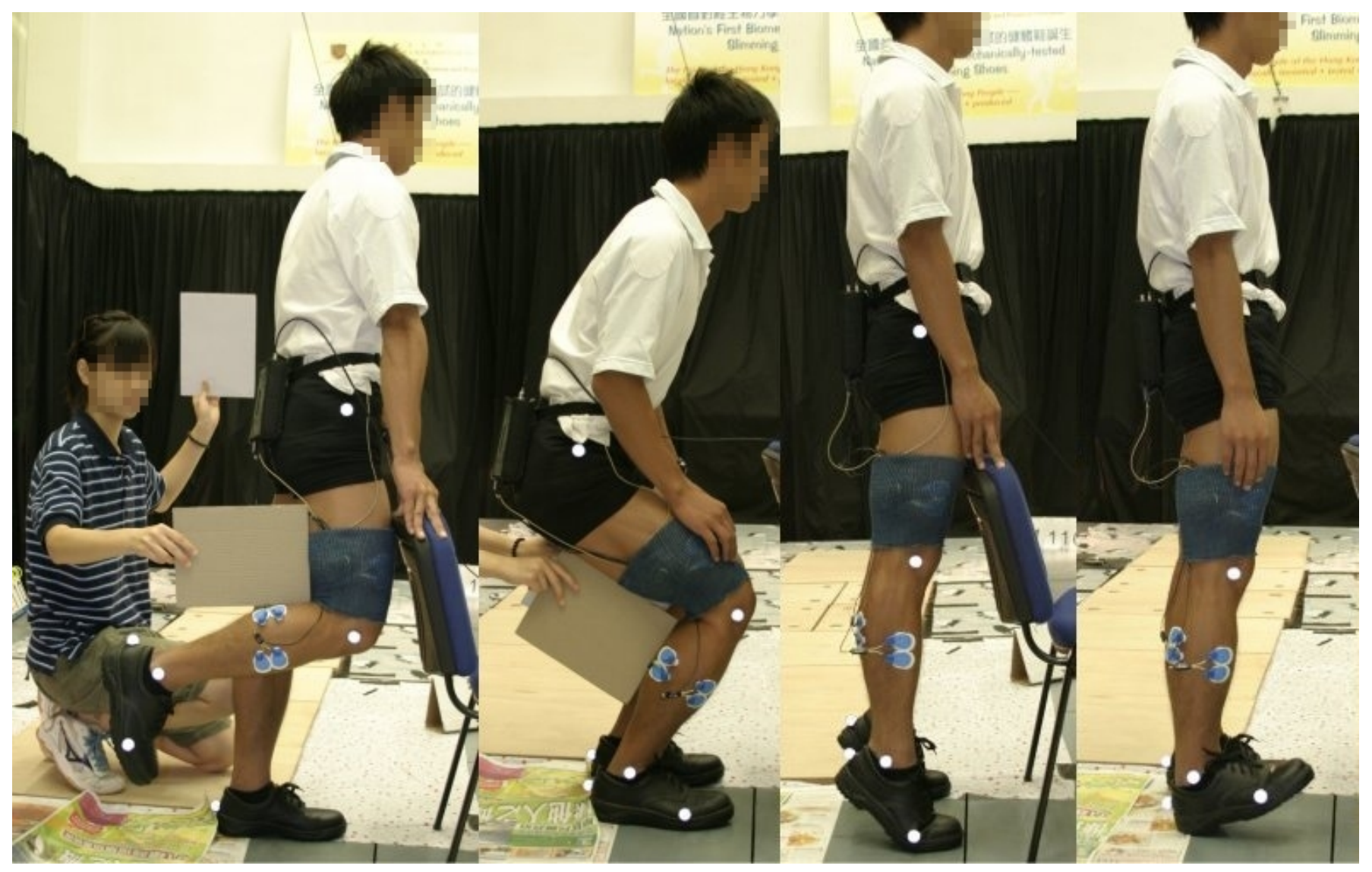

Figure 4 - Postures for submaximal isometric contraction normalization for biceps femoris (lower leg raise), rectus femoris (semi-squatting), gastrocnemius (plantar flexion), and tibialis anterior (dorsiflexion) (from left to right). 


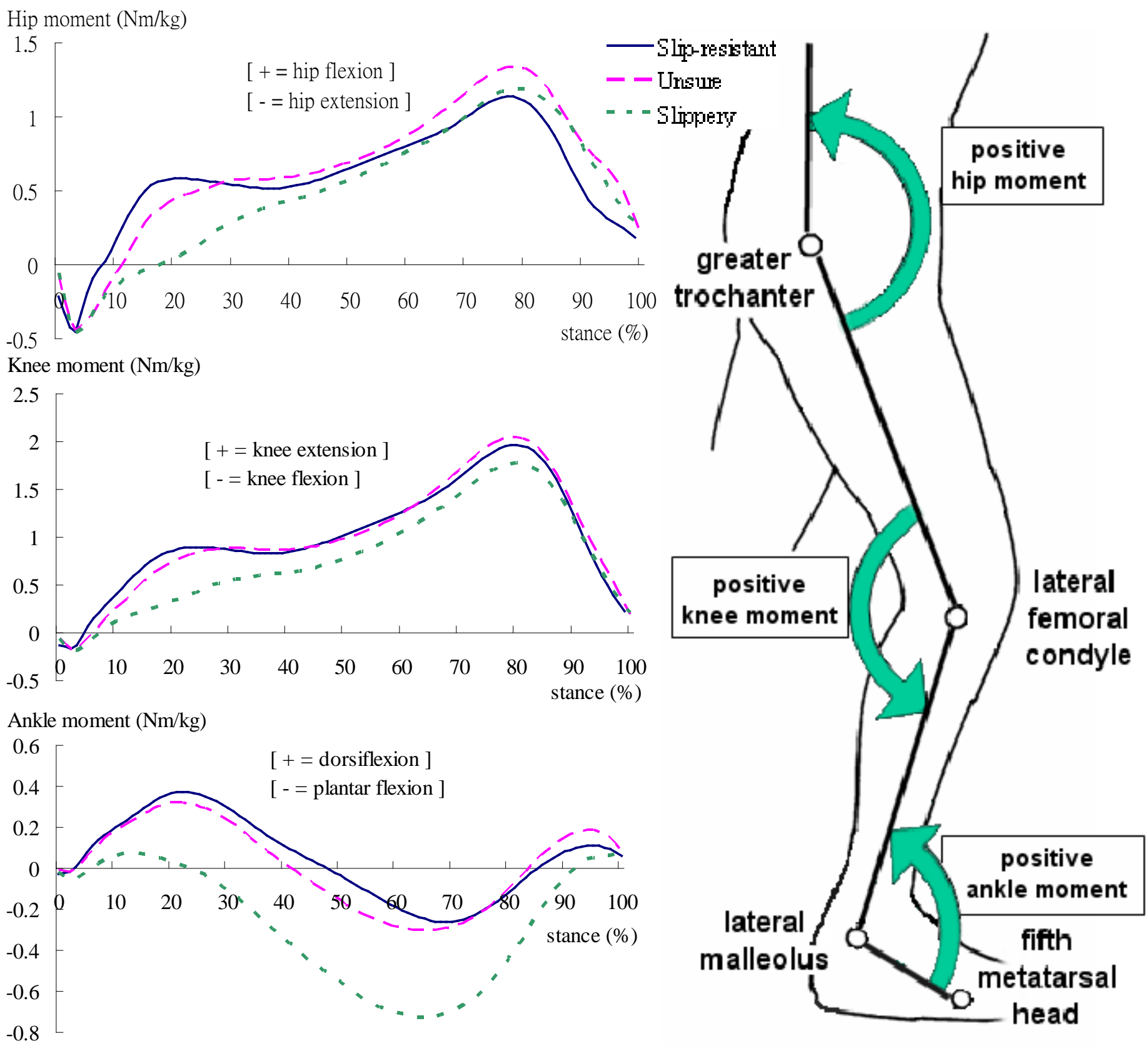

Figure 5 - Lower extremity joint moment profile from foot strike ( $0 \%$ stance) to foot take-off (100\% stance) 

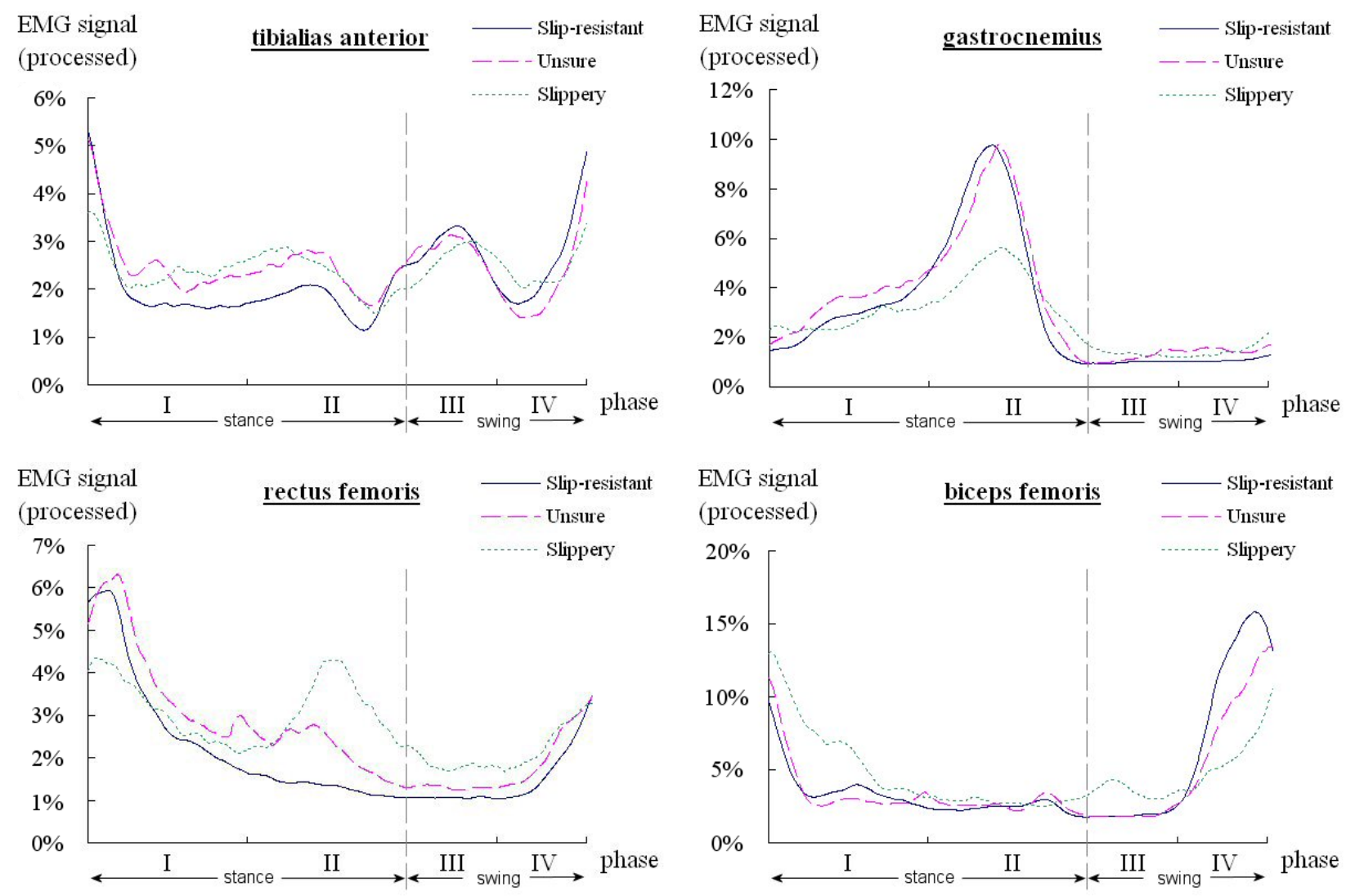

Figure 6 - Processed EMG signal profile of the four muscles for one stride (from phase I to IV) 